oxide ceramics, and the use of gas phase reactions. There are additional chapters on hydrothermal synthesis and non-aqueous liquid phase reactions, with an appendix on the determination of powder particle size. The chapters deal predominantly with the methods for fabricating powders that can then be introduced into subse- quent forming and sintering processes, the powders being especially suitable by virtue of their homogeneity, size, size distribution, and shape. Attention also is given to the so-called "powder-free" preparation routes in which chemistry provides methods for direct precursor to component conversion.
The book brings into perspective the different methods and mentions each of the major research directions. The comprehensive references are also a helpful guide to the wider literature.

Reviewer: Richard I. Brook is Cookson Professor of Materials Science in the Department of Materials, Oxford University, England.

\title{
CLASSIFIED
}

\section{Positions Available}

\section{TENURE-TRACK POSITION \\ Materials Department University of California, Santa Barbara}

The Department of Materials at the University of California, Santa Barbara, is reopening its search for applicants for a tenure-track faculty position available July 1, 1993 in the area of the use, application, and development of computer modeling and simulation in materials science and engineering. The Materials Department has a multidisciplinary focus on such areas as electronic materials, macromolecules, structural composites, and materials processing. Applicants should have a desire to pursue interdisciplinary research within the framework of the Department and in the context of a College of Engineering initiative in numerical simulation. Individuals are encouraged to apply who have particular interests in electron structure calculation, or in areas such as molecular and polymer dynamics, simulation of interface and surface properties and growth, modeling of phase transformations, simulation of deformation processing, and modeling of mechanical properties of advanced composites.

Responsibilities include teaching both undergraduate and graduate courses and developing a strong research program. A $\mathrm{PhD}$ or an equivalent degree and evidence of excellent teaching and research are required. Senior-level appointments with tenure can be made based on an outstanding record of research. Joint appointments with other Departments at UCSB are possible.

To ensure full consideration, applications should be received by the Department by April 1, 1993. All prior applicants will be automatically considered, unless they instruct the department to withdraw their application. Candidates should send a resume containing teaching and research accomplishments and the names of at least three references to:

Professor David R. Clarke, Chair

Materials Department

University of California, Santa Barbara

Santa Barbara, CA 93106

\section{ANNOUNCEMENT- \\ FACULTY POSITION IN THE MECHANICS OF MATERIALS \\ Brown University Division of Engineering}

The Division of Engineering at Brown University announces the opening of a faculty position in the Mechanics of Solids Group, available September 1,1993 . The appointment will be made at the level of assistant professor within the tenurable ranks of the University.

The appointee will be expected to teach undergraduate and graduate courses in the mechanics of solids, as well as mechanical sciences courses in the undergraduate engineering curriculum. The appointee will also be expected to develop a significant independent research program. Areas of interest include the micromechanical behavior of engineering materials and the mechanics of materials processing. Approaches of interest include theoretical, computational, and experimental methods at the continuum or atomistic levels. Applications are sought from candidates who have a $\mathrm{PhD}$ or equivalent degree and research experience in a relevant area. Applicants should have an ability to make clear and effective presentations of technical and scientific material.

Interested persons should send a detailed resume, plus the names and full mailing addresses of at least three persons who could supply letters of reference if requested, to:

Ms. Peggy Mercurio, Search Administrator

Solid Mechanics Search Committee

Box D, Division of Engineering

Brown University

Providence, RI 02912

Applicants may also submit samples of published work and a PhD thesis abstract. To ensure full consideration, applications should be received by March 1, 1993.

Brown University is an equal opportunity employer and welcomes applications from women and minorities.

\section{Send BULLETIN News to:}

\author{
Editor, MRS Bulletin, Materials Research Society \\ 9800 Mcknight Road, Pittsburgh, PA 15237 \\ FAX: (412) 367-4373
}




\section{FACULTY POSITIONS \\ University of California, Los Angeles}

The Department of Materials Science and Engineering at the University of California, Los Angeles, invites applications for two faculty positions in the following areas of materials science and engineering:

Ceramics and ceramic processing,

Composite materials,

Electronic materials.

Candidates for tenure-track positions must have demonstrated outstanding originality, ability, and breadth through graduate work or postdoctoral research. Senior-level appointments will also be considered for individuals with an exceptional record of accomplishment. Qualified minority and female candidates are encouraged to apply. Please send curriculum vitae with a list of publications, names of three references, and information on research and career interests to:

The Faculty Search Committee

Department of Materials Science and Engineering

5731 Boelter Hall

University of California, Los Angeles Los Angeles, CA 90024-1595

UCLA is an equal opportunity/affirmative action employer.

\section{Director National Materials Advisory Board}

The National Research Council is seeking a director for its National Materials Advisory Board. Responsibilities include operation and oversight of board and committee work and supervision of approximately 10 professional and administrative staff members. Requires oral and written communication skills, and management skills including staff supervision, project management, program administration, finance, budgets, organization of project tasks. Experience in policy analysis and knowledge of federal agencies procurement practices is highly desirable. Position requires PhD or equivalent, preferably in materials sciences/engineering and manufacturing, and at least 7 years experience. Please send resume to: NRC. CETS (MFL) 2101 Constitution Ave., NW, Washington, 20418. EOE.
STAFF POSITION IN SOLID STATE/MATERIALS THEORY

Sandia National Laboratories, California

The Materials Theory Group at Sandia National Laboratories in Livermore, California has an immediate opening at the staff level. The group has ongoing research activities in applications of solidstate theory to materials. Areas of specialty include band structure calculations, semi-empirical atomistic calculations, and macroscopic modelling. Interests have included alloys, clusters and growth of surface layers, dislocation structure and dynamics, structure of grain boundaries, and fracture.

Candidates for this position should send a resume (with names of references), copies of selected published papers, statement of research interests and uncertified copies of college transcripts to:

Dr. Murray Daw

c/o Marge York, Personnel, 8522-S12

Sandia National Laboratories P.O. Box 969

Livermore, CA 94551-0969

Deadline is April 15, 1993. U.S. Citizenship is required.

Equal Opportunity Employer M/FN/H.

\section{FACULTY POSITION MATERIALS SCIENCE AND ENGINEERING} Rice University

Rice University is seeking candidates for a tenure-track faculty position in the area of materials science and engineering. The rank of assistant professor is preferred, but an appointment at the rank of professor or associate professor would be considered for an exceptionally well-qualified individual. Candidates should hold a PhD in materials science or related discipline and have demonstrated abilities in conducting research. Candidates should also have a strong interest in teaching exceptional students at the undergraduate and graduate levels. The position is open to individuals with research interests in structure-property relationships in advanced engineering materials (broadly defined) for use in the field of nanotechnology, i.e., materials with characteristic dimensions in the nanometer to micron range. Examples of relevant research areas include, but are not limited to, thin films, multilayers, nanocrystalline materials, nanocomposites, nanoscale fabrication, and surface modification. Rice University is developing a multidisciplinary program in this area. The desired starting date is July $1,1993$.

Interested parties should send a complete resume, publication list, and the names of at least three references (addresses, phone, and fax numbers) to: Professor George M. Pharr, Department of Mechanical Engineering and Materials Science, Rice University, P.O. Box 1892, Houston, TX 77251. Applications should be received by March 31, 1993.

\section{Swiss Federal Institute of Technology-Lausanne \\ Ecole Polytechniques \\ Federale-Lausanne}

Applications are invited for the following positions in the Department of Physics:

\section{PROFESSOR OF NANOSTRUCTURES \\ AND ASSISTANT PROFESSOR OF OPTOELECTRONICS}

The files of research cover experimental studies of light-electron interactions in quantum semiconductor structures and the development and study of solid-state optoelectronic components for applications in the field of information technology, sensors and actuators, respectively. The candidates are expected to participate in physics teaching at the undergraduate and graduate level.

Female candidates are especially encouraged to apply.

The deadline for the receipt of applications is February 28 , 1993. Interested candidates should ask for an application form from:

Presidence de l'Ecole Polytechnique

Federale de Lausanne

CE-Ecublens

1015 LAUSANNE, SUISSE 


\section{Positions Available}

\section{FACULTY POSITION EXPERIMENTAL CONDENSED MATTER PHYSICS}

The Department of Physics and Astronomy at the University of Alabama has a tenure-track faculty position at the assistant professor level in the area of materials for information storage. The successful candidate should have a PhD degree with publications in an appropriate area, good communication skills, and a strong interest in undergraduate and graduate teaching. Postdoctoral experience is desirable. The selected candidate will be expected to participate cooperatively in the Center for Materials for Information Technology, a multidisciplinary research program involving several academic departments. Presently, research is being conducted on high magnetization particles and films, thin films exhibiting giant magnetoresistance, magnetic time decay, high-speed magnetization reversal, and other topics relevant to information storage. Please send a complete resume, a publication list, a statement of research and teaching interests, and the names of three references by March 1 (or until a suitable candidate is hired) to Prof. William D. Doyle, Department of Physics and Astronomy, University of Alabama, P.O. Box 870324, Tuscaloosa, AL 35487. 0234.

The University of Alabama is an equal opportunity' affirmative action employer.
POSTDOCTORAL POSITION IN SOLID-STATE/MATERIALS THEORY

\section{Sandia National Laboratories, California}

The Materials Theory Group at Sandia National Laboratories in Livermore, California has an immediate opening for a postdoctoral appointment. The group has ongoing research activities in applications of solid-state theory to materials. Areas of specialty include band structure calculations, semi-empirical atomistic calculations, and macroscopic modelling. Interests have included alloys, clusters and growth of surface layers, dislocation structure and dynamics, structure of grain boundaries, and fracture.

Candidates for this position should send a resume (with names of references), copies of selected published papers, statement of research interests, and uncertified copies of college transcripts to:

Dr. Murray Daw

c/o Marge York, Personnel, 8522-S13

Sandia National Laboratories

P.O. Box 969

Livermore, CA 94551-0969

Deadline is April 15, 1993. U.S. Citizenship is required.

Equal Opportunity Empioyer M/FN/H.
FACULTY POSITION IN MATERIALS SCIENCE

\section{California Institute of Technology}

The Materials Science program invites applications for a tenure-track faculty position. Junior faculty appointments are made initially for four years, contingent upon completion of the PhD. Exceptionally well-qualified applicants will be considered for a tenured appointment. Candidates must have a demonstrated ability for conducting high-quality research in materials science or a similar field, and be willing to participate in the teaching program at the graduate and undergraduate levels. Applicants must send a detailed curriculum vitae with a list of publications and must ensure that three letters of recommendation are sent to:

Materials Science Search Committee

Keck Laboratory MS 138-78

California Institute of Technology

Pasadena, CA 91125

Fax: (818) 795-1547 Caltech is an Equal Opportunity/Affirmative
Action Employer. Women and minorities are encouraged to apply.

\section{Positions Wanted}

Research/Postdoctoral position in Industrial or Academic R\&D in Processing, Development \& Characterization of Materials. MS, PhD-Materials Eng.; BS-Chem. Eng. Background in Glass, Ceramics, Solid-state Physics/Chemistry; Spectroscopy, XRD, TEM, SEM, BET, High Temp. Furnaces/ Sintering, Computerized Data Acquisition, Structure-Property Relationships. Excellent communication skills and well published. Please reply to Box XVIII, No. 1.

\section{TO REPLY TO BOX NUMBER, WRITE:} Box __, No. __, c/o MRS Bulletin Materials Research Society 9800 McKnight Road Pittsburgh, PA 15237

\section{Coming in April...}

Guest Editor Robert Newnham, Pennsylvania State University, will focus on the intriguing subject of Smart Materials. Articles on this topic will include:

Sensors, Actuators, and Smart Materials, by Susan Trolier-McKinstry and Robert Newnham, Pennsylvania State University;

Magnetostrictive Materials, by Kristl B. Hathaway and Arthur E. Clark, Naval Surface Warfare Center;

Ceramic Actuators-Principles and Applications, by Kenji Uchino, Pennsylvania State University; and

Shape Memory Alloys, by C.M. Wayman, University of Illinois.

\author{
Ad closing for the April MRS Bulletin is \\ March 1, 1993. \\ To place your ad, call \\ Mary E. Kaufold at (412) 367-3036 today!
}

